\title{
SOX2 and SOX12 are predictive of prognosis in patients with clear cell renal cell carcinoma
}

\author{
WEIJIE GU ${ }^{1,2^{*}}$, BEIHE WANG ${ }^{1,2^{*}}$, FANGNING WAN ${ }^{1,2^{*}}$, JUNLONG WU $^{1,2}$, XIAOLIN LU $^{1,2}$,

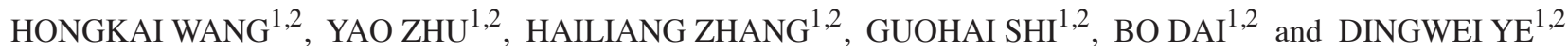 \\ ${ }^{1}$ Department of Urology, Fudan University Shanghai Cancer Center; \\ ${ }^{2}$ Department of Oncology, Shanghai Medical College, Fudan University, Shanghai 200032, P.R. China
}

Received October 21, 2016; Accepted September 28, 2017

DOI: $10.3892 / 01.2018 .7828$

\begin{abstract}
Sex-determining region Y-box protein (SOX) genes serve an important role in cancer growth and metastasis. The present study aimed to determine the predictive ability of SOX and associated genes identified through molecular network in clear cell renal cell carcinoma (RCC). A total of 505 patients with clear cell RCC from The Cancer Genome Atlas (TCGA) cohorts were collected in this study. The expression profile of SOX and associated genes were obtained from the TCGA RNAseq database. Clinicopathological characteristics, including age, gender, tumor grade, stage, laterality disease-free-survival and overall survival (OS) were collected. Cox's proportional hazards regression model, as well as Kaplan-Meier curves were used to assess the relative factors. Selected genes of SOXs that demonstrated significant associations with OS were further validated in 192 patients from the validation cohort. In the univariate Cox regression model, SOX1, SOX2, SOX6, SOX11, SOX12, SOX13, SOX15, SOX17 and SOX30 expression were predictive in the prognosis of clear cell RCC. Following adjustment for clinical factors, SOX2 [hazard ratio (HR), 1.130; 95\% confidence interval (CI), 1.002-1.275), SOX12 (HR, 1.379; 95\% CI, 1.060-1.793) and SOX15 (HR, 1.245; 95\% CI, 1.063-1.459) remained statistically significant. Furthermore, POU class 5 homeobox 1 (POU5F1), POU2F1 and nuclear receptor subfamily 5 group A member 1 in the gene cluster network analysis associated with SOX2 did not reduce the statistical significance when added to the multivariate analysis. The findings were extended to the Fudan University Shanghai Cancer Center cohort. The results revealed that high SOX2 and SOX12 expression
\end{abstract}

Correspondence to: Professor Dingwei Ye, Department of Oncology, Shanghai Medical College, Fudan University, 270 Dong'an Road, Shanghai 200032, P.R. China

E-mail: dwyeli_00@126.com

*Contributed equally

Key words: SOX2, SOX12, prognosis, clear cell renal cell carcinoma, TCGA were associated with poor prognosis for OS (log-rank test, all $\mathrm{P}<0.05)$. SOX2 and SOX12 were identified as independent prognostic factors of OS in clear cell RCC.

\section{Introduction}

Renal cell carcinoma (RCC) accounts for $\sim 2-3 \%$ of all malignancies worldwide (1). Despite an increasing proportion of patients with early stage tumors at diagnosis and the development of novel treatment strategies, a quarter still present with locally advanced or metastatic disease, and eventually, one third of patients submitted to surgical nephrectomy develop recurrence, or metastasis (2). The clinical outcomes of RCC vary widely, emphasizing the need for prompt and accurate prognostic stratification. To date, the best prognostic system for overall survival (OS) is the tumor node metastasis (TNM) staging system in RCC, although it is insufficient to significantly improve the management of patients $(3,4)$. Important prognostic factors of RCC include tumor size, histological subtype, nuclear grade, local extent of the tumor and evidence of metastatic disease at presentation (5). Therefore, identification of novel reliable predictive and independent prognostic factors is critical for improving therapeutic modalities and for prolonging the survival of patients with RCC.

Sex-determining region Y (SRY)-box protein (SOX) genes arise from the founding member Sry, the mammalian testis-determining factor. Currently, $20 \mathrm{SOX}$ proteins are known in mammals and characterized by a conserved high mobility group DNA-binding domain (6,7). Members of the SOX family are developmental regulators with functions in sex determination, chondrogenesis, hematopoiesis, neural crest development and neurogenesis (8). Numerous findings support the involvement of different SOX genes in cancer development. The expression of SOX genes is reported to be associated with prognosis in various cancer types, including lung $(9,10)$, brain (11), hepatocellular (12), gastric (13), prostate (14) and cervical squamous cell carcinoma (15). However, the potential role of SOX family members in RCC, and its biological functions on the initiation, progression and outcome of the disease remain unclear. Therefore, the present study aimed to analyze the prognostic value of SOX genes in patients with RCC using public database and validate these findings in a patient cohort. 


\section{Materials and methods}

Patients and samples. The Cancer Genome Atlas (TCGA) database makes available gene expression level and clinical data on RCC from the website of Cancer Genomics Browser of University of California Santa Cruz (https://genome-cancer. ucsc.edu/). Only patients with fully characterized tumors, intact OS, disease-free survival (DFS), and RNAseq information were included as described previously (16). Patients receiving pretreatment were excluded. Clinicopathological characteristics, including age, gender, tumor size, TNM stage, tumor grade, stage, laterality, OS and DFS were collected. A total of 16 patients whose samples were confirmed with non-clear cell RCC were excluded (17). Finally, 505 patients confirmed with primary clear cell RCC with detailed SOX expression data were included in the current study.

Network analysis of genes that were associated with OS was performed using the tools from cBioPortal (http://www. cbioportal.org/public-portal/cgds_r.jsp). Genes were considered in the same network if they were in the same complex or interacted with each other with $>12 \%$ of changes. Information from 20 members of the SOX family and the associated genes obtained from the TCGA RNAseq database are listed in Table IV.

In order to validate the prognostic value of these genes, a validation cohort from Fudan University Shanghai Cancer Center (FUSCC; Shanghai, China) was established, including 192 patients with histologically confirmed clear cell RCC between February 2009 and June 2012 who underwent radical nephrectomy or nephron sparing nephrectomy. Patient characteristics parallel to TCGA data, including age, gender, tumor size, TNM stage, tumor grade, stage and tumor position were obtained from clinical records. Patients with missing data on the aforementioned variables were excluded.

Trained research nurses followed up the cohort by telephone once every 3-6 months, and recorded the events of clinical interest, including tumor recurrence, progression and metastasis. All tissue samples were collected during surgeries and stored at $-70^{\circ} \mathrm{C}$ in the tissue bank of FUSCC.

The present study was approved by the institutional review board of FUSCC and written informed consent was obtained from all patients.

RNA extraction and reverse transcription-quantitative polymerase chain reaction $(R T-q P C R)$ analysis. For the validation cohort, 192 frozen tissue samples $(100 \mathrm{mg})$ were harvested and ground into a fine powder. Total RNA was isolated using TRIzol ${ }^{\circledR}$ reagent (cat. no. 15596-026; Invitrogen, Thermo Fisher Scientific, Inc.). A PrimeScript RT reagent kit (cat. no. K1622, Thermo Fisher Scientific, Inc.) was used to synthesize first strand cDNA from total RNA according to the manufacturer's protocol. Next, SYBR-Green RT-qPCR assays were performed using an ABI 7900HT system (Applied Biosystems; Thermo Fisher Scientific, Inc.). The thermocycling conditions were as follows: $50^{\circ} \mathrm{C}$ for $5 \mathrm{~min}, 95^{\circ} \mathrm{C}$ for $2 \mathrm{~min}$ followed by 40 cycles of $95^{\circ} \mathrm{C}$ for $3 \mathrm{sec}$ and $60^{\circ} \mathrm{C}$ for $30 \mathrm{sec}$. The expression level of RNA was normalized to the level of $\beta$-actin with $2^{-\triangle \Delta C q}$ method (18). The primers for RT-qPCR analysis were synthesized by Sangon Biotech Co., Ltd. (Shanghai, China) and the sequences were as follows: SOX2 forward,
5'-TGGACAGTTACGCGCACAT-3' and reverse, 5'-CGAGTA GGACATGCTGTAGGT-3'; SOX12 forward, 5'-AAGAGG CCGATGAACGCATT-3' and reverse, 5'-TAGTCCGGGTAA TCCGCCAT-3'; SOX15 forward, 5'-GCGACTACCCCGACT ACAAG-3' and reverse, 5'-TTGCAGTGGGAAGAGCCA TA-3'; $\beta$-actin forward, 5'-AGCGAGCATCCCCCAAAGTT-3' and reverse, 5'-GGGCACGAAGGCTCATCATT-3'.

Statistical analysis. Survival endpoints were mortality due to any cause for OS and recurrence at any site for DFS. DFS and OS rates were calculated based on the Kaplan-Meier method, and the curves were compared with log-rank tests. Variables of SOX gene expression with $\mathrm{P}<0.10$ in univariate and multivariate Cox's proportional hazard models in the TCGA cohort were selected for further study. The final Cox's Proportional Hazards model, including clinical data and genes in the network associated with OS was performed in TCGA, and validation cohorts. Categorical data were analyzed using Fisher's exact $\chi^{2}$ test. Continuous data were analyzed using a Student's t-test. All the statistical analyses were performed using SPSS software version 20.0 (IBM Corp., Armonk, NY, USA). Two-tailed $\mathrm{P}<0.05$ was considered to indicate a statistically significant difference.

\section{Results}

Clinical characteristics in TCGA and validation cohorts. In the TCGA cohort, the median age of the 505 patients with clear cell RCC was 60.6 years old, ranging between 26 and 90 years old. A total of $325(64.4 \%)$ were male patients and $180(35.6 \%)$ were female patients. Tumor size, TNM stage, tumor grade, stage and laterality are presented in Table I. The median OS of this cohort was 79.5 months and 163 patients succumbed during the follow up. In the validation cohort, the median age of the 192 patients with clear cell RCC was 55.5 years old, ranging between 25 and 86 years old. A total of $135(70.3 \%)$ were male patients and 57 (29.7\%) were female patients. Tumor size, TNM stage, tumor grade, stage and tumor position are presented in Table I. The median OS of this cohort was 50.2 months and 42 patients succumbed during follow up.

SOX gene expression and the clinical outcomes in the TCGA, and validation cohorts. In the univariate Cox's proportion hazard ratio analysis, age, $\mathrm{T}$ stage, metastasis, tumor stage, tumor grade, hemoglobin level, white blood cell count and platelet count, expression of SOX1, SOX2, SOX6, SOX7, SOX11, SOX12, SOX13, SOX15, SOX17, and SOX30 were significantly associated with prognosis regarding OS in patients with clear cell RCC in the TCGA cohorts (Table II). Subsequently, the variables with significance in the univariate analysis were used for further multivariate analysis. After adjustment for all the potential prognostic factors, analysis indicated that age [hazard ratio (HR), 1.032; 95\% confidence interval (CI), 1.018-1.047; $\mathrm{P}<0.001]$, tumor stage (HR, 1.995; 95\% CI, 1.411-2.820; $\mathrm{P}<0.001)$, tumor grade $(\mathrm{HR}$, $1.300 ; 95 \%$ CI, 1.020-1.657; P=0.034), SOX2 (HR, 1.130; 95\% CI, 1.002-1.275, P=0.046), SOX12 (HR, 1.379; 95\% CI, 1.060-1.793; $\mathrm{P}=0.017)$ and SOX15 (HR, 1.245; 95\% CI, 1.063-1.459; $\mathrm{P}=0.007)$ were independent predictors of OS 
Table I. Clinical characteristics of patients with clear cell RCC.

\begin{tabular}{|c|c|c|c|c|c|}
\hline & TCGA cohort & $\mathrm{N}=505$ & Validation cohort & $\mathrm{N}=192$ & \\
\hline Variable & $\mathrm{N}$ & $\%$ & $\mathrm{~N}$ & $\%$ & P-value \\
\hline Age, median (range) & $60.6^{\mathrm{c}}$ & $(26-90)$ & $55.5^{\mathrm{d}}$ & $(25-86)$ & $<0.01^{\mathrm{a}}$ \\
\hline Sex & & & & & $0.16^{\mathrm{b}}$ \\
\hline Male & 325 & 64.4 & 135 & 70.3 & \\
\hline Female & 180 & 35.6 & 57 & 29.7 & \\
\hline Grade & & & & & $0.80^{\mathrm{b}}$ \\
\hline $1 \& 2$ & 232 & 46.0 & 87 & 45.3 & \\
\hline $3 \& 4$ & 269 & 53.3 & 105 & 54.7 & \\
\hline Gx & 1 & 0.2 & 0 & 0 & \\
\hline pT & & & & & $<0.01^{\mathrm{b}}$ \\
\hline $\mathrm{T} 1$ & 257 & 50.9 & 137 & 71.4 & \\
\hline $\mathrm{T} 2$ & 63 & 12.5 & 26 & 13.5 & \\
\hline $\mathrm{T} 3$ & 175 & 34.7 & 24 & 12.5 & \\
\hline $\mathrm{T} 4$ & 10 & 2.0 & 5 & 2.6 & \\
\hline $\mathrm{N}$ & & & & & $<0.01^{\mathrm{b}}$ \\
\hline No & 226 & 44.8 & 183 & 95.3 & \\
\hline N1 & 17 & 3.4 & 2 & 1 & \\
\hline $\mathrm{Nx}$ & 262 & 51.9 & 7 & 3.6 & \\
\hline M & & & & & $<0.01^{\mathrm{b}}$ \\
\hline M0 & 402 & 79.6 & 184 & 95.8 & \\
\hline M1 & 78 & 15.4 & 7 & 3.6 & \\
\hline $\mathrm{Mx}$ & 23 & 4.6 & 1 & 0.5 & \\
\hline AJCC 7th edition stage & & & & & $<0.01^{\mathrm{b}}$ \\
\hline I & 252 & 49.9 & 136 & 70.8 & \\
\hline II & 51 & 10.1 & 24 & 12.5 & \\
\hline III & 122 & 24.2 & 24 & 12.5 & \\
\hline IV & 80 & 15.8 & 8 & 4.2 & \\
\hline Position & & & & & $<0.01^{\mathrm{b}}$ \\
\hline Left & 237 & 46.9 & 87 & 45.4 & \\
\hline Right & 266 & 52.7 & 98 & 51 & \\
\hline Bilateral & 2 & 0.4 & 7 & 3.6 & \\
\hline
\end{tabular}

${ }^{\mathrm{a} t-t e s t ;}{ }^{\mathrm{b}} \chi^{2}$ test; ${ }^{\mathrm{c}}$ The median age of TCGA cohort was $60.6 \mathrm{yr}$; ${ }^{\mathrm{d}}$ The median age of validation cohort was $55.5 \mathrm{yr}$. pT, tumor stage; N, node; M, metastasis; TCGA, The Cancer Genome Atlas; RCC, renal cell carcinoma.

(Table II). Finally, the expression levels of SOX2, SOX12 and SOX15 were selected for further study.

To further evaluate the prognostic value of SOX2, SOX12 and SOX15, the continuous variables were dichotomized by the median cut-off value ( 0.47 for SOX2; 9.22 for SOX12; 3.14 for SOX15). Kaplan-Meier curves demonstrated that high expression of SOX2, SOX12 and SOX15 was associated with poor prognosis for OS, and DFS (Fig. 1).

The interaction network was established based on three situations, stated as 'react with', 'in same component' and 'state change'. The cut-point of state change was set as $12 \%$ (16). As a result, POU class 5 homeobox 1 (POU5F1), POU2F1 and nuclear receptor subfamily 5 group A member 1 (NR5A1) were identified to be associated with SOX2, and added to the multivariate Cox's proportional hazard model. Multivariate analysis revealed that the expression of SOX2 (HR, 1.123; 95\% CI, 1.001-1.272; $\mathrm{P}=0.047$ ), SOX12 (HR, 1.360; 95\% CI, 1.026-1.803; $\mathrm{P}=0.033$ ) and SOX15 (HR, 1.269; 95\% CI, 1.072-1.501; $\mathrm{P}=0.006)$ remained significantly associated with the OS of patients with clear cell RCC in the cohort (Table II). However, when the results were validated in the FUSCC cohort, only SOX2 and SOX 12 were significant predictors of OS (Fig. 1).

Multivariate logistic regression analysis was performed to determine clinical factors that may affect the expression of SOX2 and SOX12. Tumor stage [odds ratio (OR), 1.257; 95\% CI, 1.053-1.501; $\mathrm{P}=0.011]$ and tumor grade $(\mathrm{OR}, 1.436,95 \% \mathrm{CI}$, 1.086-1.898; $\mathrm{P}=0.011)$ were significantly associated with SOX12 expression, while only tumor stage (OR, 1.954; 95\% CI, 1.069-1.518; $\mathrm{P}=0.007)$ was significantly associated with SOX2 expression (Table III). 
Table II. Univariate and multivariate survival analysis of SOXs family and related genes for patients with clear cell RCC in the TCGA cohort.

\begin{tabular}{|c|c|c|c|c|c|c|}
\hline \multirow[b]{2}{*}{ Variable } & \multicolumn{2}{|l|}{ Univariate } & \multicolumn{2}{|c|}{ Multivariate } & \multicolumn{2}{|c|}{ Multivariate } \\
\hline & HR $(95 \% \mathrm{CI})$ & P-value & $\operatorname{HR}(95 \% \mathrm{CI})$ & P-value & HR $(95 \%$ CI $)$ & P-value \\
\hline Age & $1.028(1.015-1.041)$ & $<0.001$ & $1.032(1.018-1.047)$ & $<0.001$ & $1.033(1.018-1.049)$ & $<0.001$ \\
\hline Gender $^{\mathrm{a}}$ & $0.950(0.693-1.302)$ & 0.752 & $0.947(0.666-1.346)$ & 0.760 & $0.968(0.676-1.386)$ & 0.859 \\
\hline $\mathrm{T}$ & $1.992(1.685-2.355)$ & $<0.001$ & $0.764(0.531-1.097)$ & 0.145 & $0.716(0.489-1.049)$ & 0.087 \\
\hline $\mathrm{N}^{\mathrm{a}}$ & $0.992(0.562-1.752)$ & 0.978 & $0.845(0.714-1.002)$ & 0.052 & $0.860(0.723-1.023)$ & 0.089 \\
\hline$M^{\mathrm{a}}$ & $2.459(1.921-3.149)$ & $<0.001$ & $1.237(0.780-1.962)$ & 0.367 & $1.178(0.721-1.924)$ & 0.513 \\
\hline Stage & $1.954(1.707-2.236)$ & $<0.001$ & $1.995(1.411-2.820)$ & $<0.001$ & $2.083(1.432-3.031)$ & $<0.001$ \\
\hline Grade & $2.398(1.941-2.965)$ & $<0.001$ & $1.300(1.020-1.657)$ & 0.034 & $1.349(1.031-1.765)$ & 0.029 \\
\hline Position $^{a}$ & $0.695(0.512-0.944)$ & 0.019 & $0.740(0.532-1.028)$ & 0.073 & $0.732(0.521-1.030)$ & 0.073 \\
\hline SOX1 & 1.207 (1.106-1.317) & $<0.001$ & $0.950(0.861-1.049)$ & 0.311 & $0.961(0.867-1.065)$ & 0.450 \\
\hline SOX2 & $1.221(1.119-1.334)$ & $<0.001$ & $1.130(1.002-1.275)$ & 0.046 & $1.123(1.001-1.272)$ & 0.047 \\
\hline SOX3 & $1.087(0.909-1.300)$ & 0.361 & - & - & - & - \\
\hline SOX4 & $1.065(0.864-1.312)$ & 0.557 & - & - & - & - \\
\hline SOX5 & $0.969(0.840-1.117)$ & 0.665 & - & - & - & - \\
\hline SOX6 & $0.773(0.698-0.855)$ & $<0.001$ & $0.987(0.872-1.118)$ & 0.841 & $0.986(0.864-1.126)$ & 0.837 \\
\hline SOX7 & $0.875(0.753-1.017)$ & 0.082 & - & - & - & - \\
\hline SOX8 & $1.041(0.914-1.186)$ & 0.553 & - & - & - & - \\
\hline SOX9 & $0.942(0.836-1.062)$ & 0.330 & - & - & - & - \\
\hline SOX10 & $1.030(0.909-1.168)$ & 0.642 & - & - & - & - \\
\hline SOX11 & $1.126(1.032-1.228)$ & 0.008 & $1.094(0.981-1.219)$ & 0.107 & $1.089(0.974-1.218)$ & 0.134 \\
\hline SOX12 & $2.041(1.626-2.563)$ & $<0.001$ & $1.379(1.060-1.793)$ & 0.017 & $1.360(1.026-1.803)$ & 0.033 \\
\hline SOX13 & $0.636(0.530-0.762)$ & $<0.001$ & $0.860(0.676-1.094)$ & 0.219 & $0.867(0.666-1.128)$ & 0.289 \\
\hline SOX14 & $0.866(0.226-3.313)$ & 0.833 & - & - & - & - \\
\hline SOX15 & $1.290(1.131-1.470)$ & $<0.001$ & $1.245(1.063-1.459)$ & 0.007 & $1.269(1.072-1.501)$ & 0.006 \\
\hline SOX17 & $0.790(0.675-0.924)$ & 0.003 & $0.945(0.765-1.168)$ & 0.602 & $0.962(0.773-1.197)$ & 0.729 \\
\hline SOX18 & $0.847(0.859-1.133)$ & 0.986 & - & - & - & - \\
\hline SOX21 & $0.946(0.803-1.114)$ & 0.506 & - & - & - & - \\
\hline SOX30 & $1.216(1.0371 .425)$ & 0.016 & $1.132(0.950-1.348)$ & 0.167 & $1.116(0.930-1.338)$ & 0.237 \\
\hline POU5F1 & & & & & $0.983(0.883-1.095)$ & 0.754 \\
\hline POU2F1 & & & & & $0.947(0.727-1.233)$ & 0.685 \\
\hline NR5A1 & & & & & $1.026(0.894-1.178)$ & 0.716 \\
\hline
\end{tabular}

${ }^{a}$ Categorical variables: male patients vs. female patients; pathological lymph node positive or otherwise; M0 vs. M1; left vs. right. 95\% CI, 95\% confidence interval; HR, hazard ratio; TCGA, The Cancer Genome Atlas; SOX, SRY (sex determining region Y)-box; POU5F1, POU class 5 homeobox 1; NR5A1, Nuclear receptor subfamily 5 group A member 1; RCC, renal cell carcinoma.

\section{Discussion}

To the best of our knowledge, for the first time, the present study has demonstrated that expression of SOX family genes was associated with OS in patients with clear cell RCC. Multivariate analysis revealed that SOX2, SOX12 and SOX15 may serve an important role in the prognosis of patients with clear cell RCC. When validated in the cohort from FUSCC, SOX2 and SOX12 remained independent prognostic factors.

SOX family members participate in numerous important biological processes, particularly in cell differentiation during embryonic development. It has been considered that the origins of cancer may be associated with the aberrant reactivation of embryonic development or stem cell programs within normal tissues. Conversely, numerous oncogenes and tumor suppressor genes were also identified to be essential in embryogenesis (19). SOX2, known as a major stemness marker, is high expressed in cancer stem cells, which have the ability to renew itself and generate the diversity of cell types. It is considered that SOX 2 confers a less differentiated phenotype and its high level of expression may promote a potential for metastasis (20). SOX12 may act as oncogenes, tumor suppressor genes or both depending on the cancer types. In squamous esophageal, colorectal and small cell lung cancer, SOX2 is associated with poor prognosis, and is activated through DNA amplification (21-24). However, SOX 2 acts as tumor suppressor gene in gastric cancer and non-small cell lung cancers (25-27), which further 
A

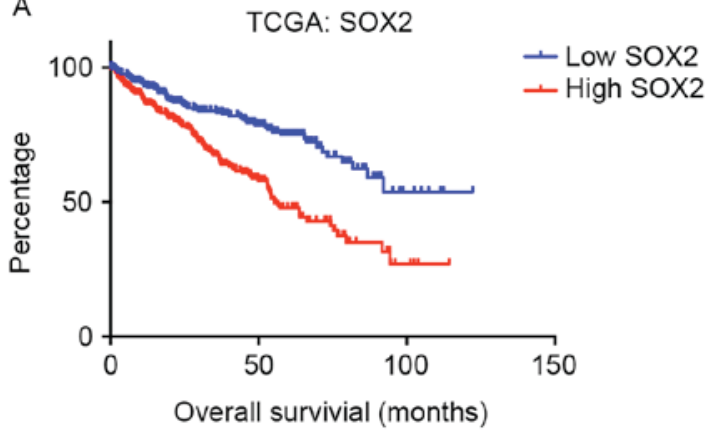

C

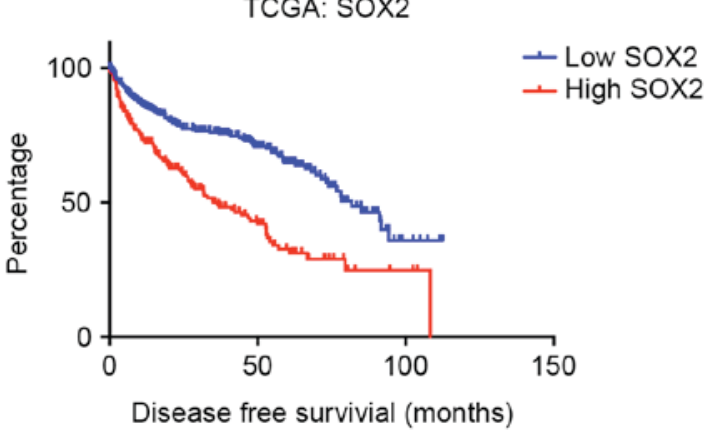

E

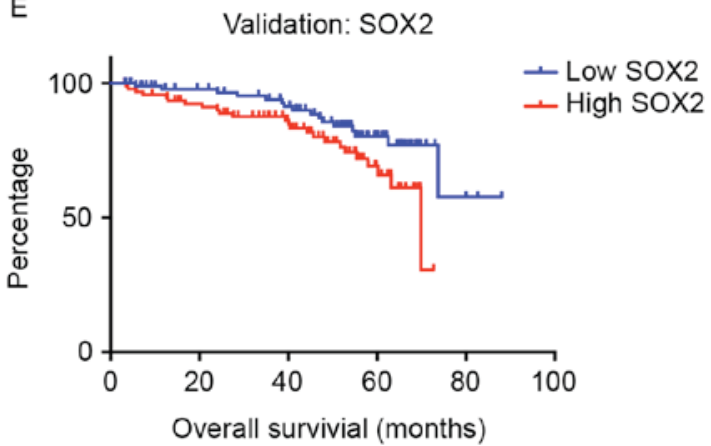

B

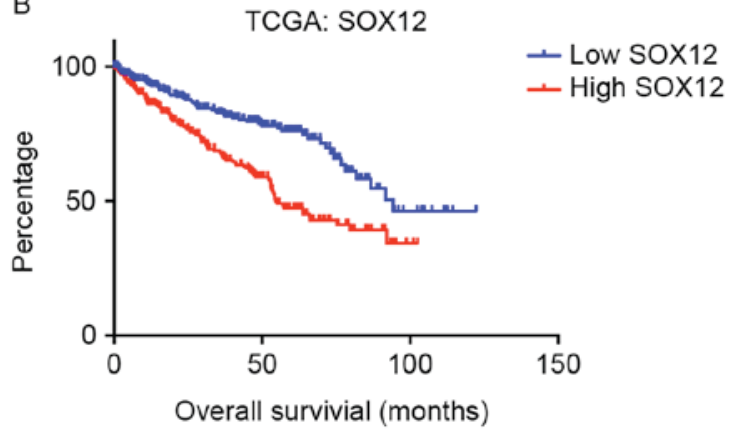

D

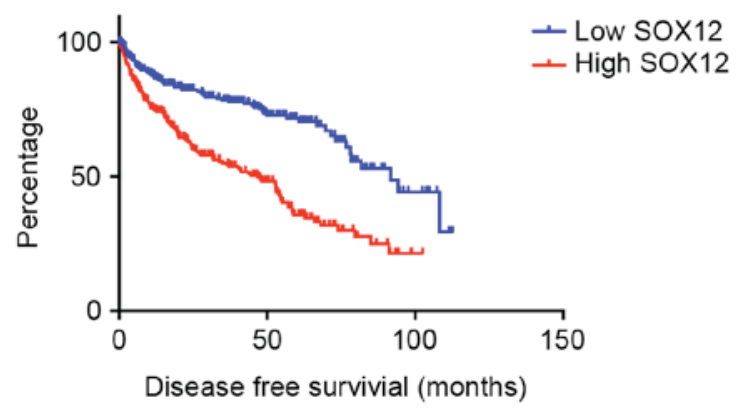

$\mathrm{F}$

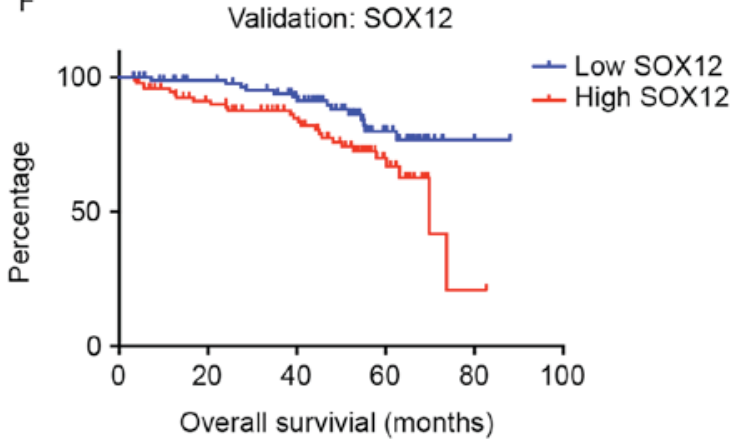

Figure 1. Kaplan-Meier plots of survival in the TCGA and validation cohorts are presented according to SOX2 and SOX12 expression. Kaplan-Meier estimates of overall survival are shown according to the expression level of (A) SOX2 and (B) SOX12 in the TCGA cohort. Kaplan-Meier estimates of disease-free survival are shown according to the expression level of (C) SOX2 and (D) SOX12 in the TCGA cohort. Kaplan-Meier estimates of overall survival are shown according to the expression level of (E) SOX2 and (F) SOX12 in the validation cohort. TCGA, The Cancer Genome Atlas; SOX, Sex-determining region Y-box protein.

emphasizes the context-specific nature of SOX involvement in carcinogenesis.

SOX12 is a member of group $\mathrm{C}$ of SOX transcription factors. Another two members named SOX4 and SOX11 were reported to serve key roles in cardiac, neuronal, and other major developmental processes, as well as be involved in cancer development, but the roles of SOX12 remain unknown $(7,28)$. A recent study revealed that SOX12 had significant prognostic value in human hepatic cell carcinoma. Overexpression of SOX12 was significantly correlated with loss of tumor encapsulation, microvascular invasion and a higher tumor-nodule-metastasis stage. Furthermore, SOX12 expression was an independent and significant risk factor for recurrence, and reduced survival time following curative resection (29). The underlying mechanism may be that SOX12 expression was positively associated with Twist1, fibroblast growth factor binding protein 1 and forkhead box Q1 expression levels, which serve a central role in tumor invasion, and metastasis (29). However, in colon cancer, a genome-wide screen identified SOX12 as a metastatic suppressor affecting Wnt/Tcf signaling (30). Although evidence has suggested that the SOX family serves an important role in human cancer, little is known regarding its involvement in RCC. The results of the present study indicated an association between the outcome of patients with clear cell RCC, and the expression of SOX2 and SOX12, but the underlying mechanism remains unknown.

The role of SOX15 in human cancer is also relatively understudied compared with other SOX family members. Overexpression of SOX15 was associated with worse clinical outcome in the TCGA cohort, but the result could not be validated in the FUSCC cohort. Furthermore, a previous study demonstrated that SOX15 overexpression inhibited the proliferation of human testicular embryonic carcinoma cells (31). Another study indicated SOX15 
Table III. Multivariate logistic regression analysis of factors that might affect the expression of SOX2 and SOX12 in the TCGA Cohort with clear cell RCC.

\begin{tabular}{|c|c|c|c|c|}
\hline \multirow[b]{2}{*}{ Variable } & \multicolumn{2}{|c|}{ SOX2 } & \multicolumn{2}{|c|}{ SOX12 } \\
\hline & OR $(95 \% \mathrm{CI})$ & P-value & OR $(95 \% \mathrm{CI})$ & P-value \\
\hline Age & $1.000(0.985-1.015)$ & 0.967 & $1.013(0.998-1.029)$ & 0.085 \\
\hline Gender ${ }^{\mathrm{a}}$ & $1.165(0.779-1.770)$ & 0.427 & $0.968(0.499-1.080)$ & 0.117 \\
\hline Stage & $1.954(1.069-1.518)$ & 0.007 & $1.257(1.053-1.501)$ & 0.011 \\
\hline Grade & $2.398(0.849-1.464)$ & 0.435 & $1.436(1.086-1.898)$ & 0.011 \\
\hline Position $^{\mathrm{a}}$ & $0.749(0.745-1.506)$ & 0.749 & $0.732(0.521-1.030)$ & 0.835 \\
\hline
\end{tabular}

a'Categorical variables: male patients vs. female patients; left vs. right. SOX, SRY (sex determining region Y)-box; 95\% CI, 95\% confidence interval; OR, odds ratio; TCGA, The Cancer Genome Atlas.

Table IV. Gene IDs of SOXs family members and related genes.

\begin{tabular}{lll}
\hline Official gene symbol & \multicolumn{1}{c}{ Full name } & UniGene \\
\hline SOX1 & SRY (sex determining region Y)-box 1 & Hs.202526 \\
SOX2 & SRY (sex determining region Y)-box 2 & Hs.518438 \\
SOX3 & SRY (sex determining region Y)-box 3 & Hs.157429 \\
SOX4 & SRY (sex determining region Y)-box 4 & Hs.643910 \\
SOX5 & SRY (sex determining region Y)-box 5 & Hs.657542 \\
SOX6 & SRY (sex determining region Y)-box 6 & Hs.368226 \\
SOX7 & SRY (sex determining region Y)-box 7 & Hs.709543 \\
SOX8 & SRY (sex determining region Y)-box 8 & Hs.243678 \\
SOX9 & SRY (sex determining region Y)-box 9 & Hs.647409 \\
SOX10 & SRY (sex determining region Y)-box 10 & Hs.376984 \\
SOX11 & SRY (sex determining region Y)-box 11 & Hs.432638 \\
SOX12 & SRY (sex determining region Y)-box 12 & Hs.43627 \\
SOX13 & SRY (sex determining region Y)-box 13 & Hs.201671 \\
SOX14 & SRY (sex determining region Y)-box 14 & Hs.248184 \\
SOX15 & SRY (sex determining region Y)-box 15 & Hs.95582 \\
SOX17 & SRY (sex determining region Y)-box 17 & Hs.98367 \\
SOX18 & SRY (sex determining region Y)-box 18 & Hs.8619 \\
SOX21 & SRY (sex determining region Y)-box 21 & Hs.187577 \\
SOX30 & SRY (sex determining region Y)-box 30 & Hs.529462 \\
POU5F1 & POU class 5 homeobox 1 & Hs.249184 \\
POU2F1 & POU class 2 homeobox 1 & Hs.283402 \\
NR5A1 & Nuclear receptor subfamily 5 group A member 1 & Hs.495108 \\
\hline
\end{tabular}

remarkably suppressed tumor formation via suppression of the $\mathrm{Wnt} / \beta$-catenin signaling pathway in pancreatic ductal adenocarcinoma (32).

The strength of the current study is that the clinical information was obtained from two large populations with a long-time follow-up. However, the limitation is the heterogeneous patient characteristics between the two cohorts. Secondly, the prognosis of clear cell RCC is affected by numerous factors in addition to tumor stage and tumor grade, including surgical performance, and response to adjuvant therapy. Thus, expression of SOX genes as prognostic markers in clinical routine should be further validated in a multicenter prospective study.
Taken together, SOX2 and SOX12 were identified as independent prognostic factors for OS, and DFS of clear cell RCC. This study indicated that SOX family genes may serve an important role in clear cell RCC. This novel method of identifying prognosis-associated genes may by applied in different types of cancer.

\section{References}

1. Siegel RL, Miller KD and Jemal A: Cancer statistics, 2015. CA Cancer J Clin 65: 5-29, 2015.

2. Ficarra V, Galfano A, Novara G, Iafrate M, Brunelli M, Secco S, Cavalleri S, Martignoni G and Artibani W: Risk stratification and prognostication of renal cell carcinoma. World J Urol 26: 115-125, 2008. 
3. Kim SP, Alt AL, Weight CJ, Costello BA, Cheville JC, Lohse C, Allmer C and Leibovich BC: Independent validation of the 2010 American Joint Committee on Cancer TNM classification for renal cell carcinoma: Results from a large, single institution cohort. J Urol 185: 2035-2039, 2011.

4. Edge SB and Compton CC: The American Joint Committee on Cancer: The 7th edition of the AJCC cancer staging manual and the future of TNM. Ann Surg Oncol 17: 1471-1474, 2010.

5. Sorbellini M, Kattan MW, Snyder ME, Reuter V, Motzer R, Goetzl M, McKiernan J and Russo P: A postoperative prognostic nomogram predicting recurrence for patients with conventional clear cell renal cell carcinoma. J Urol 173: 48-51, 2005.

6. Bowles J, Schepers G and Koopman P: Phylogeny of the SOX family of developmental transcription factors based on sequence and structural indicators. Dev Biol 227: 239-255, 2000.

7. Castillo SD and Sanchez-Cespedes M: The SOX family of genes in cancer development: Biological relevance and opportunities for therapy. Expert Opin Ther Targets 16: 903-919, 2012.

8. Kamachi Y and Kondoh H: Sox proteins: Regulators of cell fate specification and differentiation. Development 140: 4129-4144, 2013.

9. Castillo SD, Matheu A, Mariani N, Carretero J, Lopez-Rios F, Lovell-Badge R and Sanchez-Cespedes M: Novel transcriptional targets of the SRY-HMG box transcription factor SOX4 link its expression to the development of small cell lung cancer. Cancer Res 72: 176-186, 2012.

10. Chapman CJ, Thorpe AJ, Murray A, Parsy-Kowalska CB, Allen J, Stafford KM, Chauhan AS, Kite TA, Maddison P and Robertson JF: Immunobiomarkers in small cell lung cancer: Potential early cancer signals. Clin Cancer Res 17: 1474-1480, 2011.

11. de la Rocha AM, Sampron N, Alonso MM and Matheu A: Role of SOX family of transcription factors in central nervous system tumors. Am J Cancer Res 4: 312-324, 2014.

12. Liao YL, Sun YM, Chau GY, Chau YP, Lai TC, Wang JL, Horng JT, Hsiao M and Tsou AP: Identification of SOX4 target genes using phylogenetic footprinting-based prediction from expression microarrays suggests that overexpression of SOX4 potentiates metastasis in hepatocellular carcinoma. Oncogene 27: 5578-5589, 2008

13. Sashikawa Kimura M, Mutoh $\mathrm{H}$ and Sugano K: SOX9 is expressed in normal stomach, intestinal metaplasia, and gastric carcinoma in humans. J Gastroenterol 46: 1292-1299, 2011.

14. Matheu A, Collado M, Wise C, Manterola L, Cekaite L, Tye AJ, Canamero M, Bujanda L, Schedl A, Cheah KS, et al: Oncogenicity of the developmental transcription factor Sox9. Cancer Res 72: 1301-1315, 2012

15. Malki S, Bibeau F, Notarnicola C, Roques S, Berta P, Poulat F and Boizet-Bonhoure B: Expression and biological role of the prostaglandin D synthase/SOX9 pathway in human ovarian cancer cells. Cancer Lett 255: 182-193, 2007.

16. Lu X, Wan F, Zhang H, Shi G and Ye D: ITGA2B and ITGA8 are predictive of prognosis in clear cell renal cell carcinoma patients. Tumour Biol 37: 253-262, 2016.

17. Buttner F, Winter S, Rausch S, Reustle A, Kruck S, Junker K, Stenzl A, Agaimy A, Hartmann A, Bedke J, et al: Survival prediction of clear cell renal cell carcinoma based on gene expression similarity to the proximal tubule of the nephron. Eur Urol 68: 1016-1020, 2015

18. Livak KJ and Schmittgen TD: Analysis of relative gene expression data using real-time quantitative PCR and the 2(-Delta Delta $\mathrm{C}(\mathrm{T}))$ method. Methods 25: 402-408, 2001.
19. Garraway LA and Sellers WR: Lineage dependency and lineage-survival oncogenes in human cancer. Nat Rev Cancer 6: 593-602, 2006.

20. Lengerke C, Fehm T, Kurth R, Neubauer H, Scheble V, Müller F, Schneider F, Petersen K, Wallwiener D, Kanz L, et al: Expression of the embryonic stem cell marker SOX2 in early-stage breast carcinoma. BMC Cancer 11: 42, 2011.

21. Neumann J, Bahr F, Horst D, Kriegl L, Engel J, Luque RM, Gerhard M, Kirchner T and Jung A: SOX2 expression correlates with lymph-node metastases and distant spread in right-sided colon cancer. BMC Cancer 11: 518, 2011.

22. Lundberg IV, Löfgren Burström A, Edin S, Eklöf V, Öberg Å, Stenling R, Palmqvist R and Wikberg ML: SOX2 expression is regulated by BRAF and contributes to poor patient prognosis in colorectal cancer. PLoS One 9: e101957, 2014.

23. Yang F, Gao Y, Geng J, Qu D, Han Q, Qi J and Chen G: Elevated expression of SOX2 and FGFR1 in correlation with poor prognosis in patients with small cell lung cancer. Int J Clin Exp Pathol 6: 2846-2854, 2013.

24. Forghanifard MM, Ardalan Khales S, Javdani-Mallak A, Rad A, Farshchian M and Abbaszadegan MR: Stemness state regulators SALL4 and SOX2 are involved in progression and invasiveness of esophageal squamous cell carcinoma. Med Oncol 31: 922, 2014.

25. Wang S, Tie J, Wang R, Hu F, Gao L, Wang W, Wang L, Li Z, Hu S, Tang S, et al: SOX2, a predictor of survival in gastric cancer, inhibits cell proliferation and metastasis by regulating PTEN. Cancer Lett 358: 210-219, 2015.

26. Otsubo T, Akiyama Y, Hashimoto Y, Shimada S, Goto K and Yuasa Y: MicroRNA-126 inhibits SOX2 expression and contributes to gastric carcinogenesis. PLoS One 6: e16617, 2011.

27. Chen Y, Huang Y, Huang Y, Chen J, Wang S and Zhou J: The prognostic value of SOX2 expression in non-small cell lung cancer: A meta-analysis. PLoS One 8: e71140, 2013.

28. Thu KL, Becker-Santos DD, Radulovich N, Pikor LA, Lam WL and Tsao MS: SOX15 and other SOX family members are important mediators of tumorigenesis in multiple cancer types. Oncoscience 1: 326-335, 2014.

29. Huang W, Chen Z, Shang X, Tian D, Wang D, Wu K, Fan D and Xia L: Sox12, a direct target of FoxQ1, promotes hepatocellular carcinoma metastasis through up-regulating Twist1 and FGFBP1. Hepatology 61: 1920-1933, 2015.

30. Duquet A, Melotti A, Mishra S, Malerba M, Seth C, Conod A and Ruiz i Altaba A: A novel genome-wide in vivo screen for metastatic suppressors in human colon cancer identifies the positive WNT-TCF pathway modulators TMED3 and SOX12. EMBO Mol Med 6: 882-901, 2014

31. Yan HT, Shinka T, Sato Y, Yang XJ, Chen G, Sakamoto K, Kinoshita K, Aburatani $\mathrm{H}$ and Nakahori Y: Overexpression of SOX15 inhibits proliferation of NT2/D1 cells derived from a testicular embryonal cell carcinoma. Mol Cells 24: 323-328, 2007.

32. Thu KL, Radulovich N, Becker-Santos DD, Pikor LA, Pusic A, Lockwood WW, Lam WL and Tsao MS: SOX15 is a candidate tumor suppressor in pancreatic cancer with a potential role in Wnt/3-catenin signaling. Oncogene 33: 279-288, 2014. 